\title{
Analysis of the mutant proBA operon from a proline-producing strain of Serratia marcescens
}

\author{
Kenji Omori, ${ }^{*}$ Shin-IChi Suzuki, Yuji Imai and Saburo Komatsubara \\ Research Laboratory of Applied Biochemistry, Tanabe Seiyaku Co. Ltd, 16-89 Kashima-3-chome, Yodogawa-ku, \\ Osaka 532, Japan
}

(Received 3 October 1991; revised 10 December 1991; accepted 30 December 1991)

\begin{abstract}
The nucleotide sequence of the proBA operon from a proline-hyperproducing mutant of Serratia marcescens was determined. Two base substitutions were found: one in the proB structural gene, coding for $\gamma$-glutamyl kinase (GK), and a second one in the promoter region of the operon. The former base substitution led to a change of the predicted amino acid at position 117 from an alanine to a valine in GK. This mutation rendered GK 700-fold less sensitive to proline-mediated feedback inhibition than the wild-type enzyme. The other base substitution, a transversion from a G-C to an A-T, was located in the spacer region between the ' -35 ' and ' -10 ' sequences of the promoter, and it increased the transcriptional activity of this operon fourfold. Both these two base substitutions, which were acquired at the step of selecting mutants resistant to a toxic proline analogue, 3,4-dehydroproline, confer upon cells a high proline productivity and an increased osmotolerance.
\end{abstract}

\section{Introduction}

Proline is one of the important cellular osmolytes that are closely related to resistance to osmotic stress. The accumulation of proline decreases intracellular water potential and, therefore, makes various organisms osmotolerant (Aspinall \& Paleg, 1981; Measures, 1975). Proline accumulation can be a result of proline uptake from the medium or increased proline biosynthesis.

In micro-organisms, proline is synthesized from glutamate via three enzymic reactions, catalysed by $\gamma$-glutamyl kinase (GK; proB product), $\gamma$-glutamyl phosphate reductase (GPR ; proA product), and 1-pyrroline-5-carboxylate reductase ( $p r o C$ product). We have been working on proline metabolism in Serratia marcescens. Wild-type strains of this bacterium do not grow in minimal medium with increased osmolarity and produce only a small amount of proline (Sugiura \& Kisumi, 1985a; Sugiura et al., 1985). Proline-analogue-resistant

\footnotetext{
* Author for correspondence. Tel. 06300 2591; fax 063002593.

Abbreviations: GK, $\gamma$-glutamyl kinase; GPR, $\gamma$-glutamyl phosphate reductase: DHP, 3,4-DL-dehydroproline; TAC, L-thiazolidine-4-carboxylic acid.
}

\footnotetext{
The nucleotide sequence data reported in this paper have been submitted to GenBank, EMBL and DDBJ, and have been assigned the accession number D90351.
}

mutants have been isolated from $S$. marcescens and tested for proline productivity and osmotic stress tolerance (Sugiura \& Kisumi, 1985a, b; Sugiura et al., 1985). Some of these mutants showed enhanced proline productivity and enhanced osmotolerance. One of them, SP187, produced more than $60 \mathrm{~g}$ of L-proline $\mathrm{I}^{-1}$ in a fermentation medium (Sugiura \& Kisumi, 1985a).

We have recently determined the nucleotide sequence and the gene structure of the proBA operon from wildtype $S$. marcescens (Omori et al., 1991). S. marcescens is similar to Escherichia coli in the gene structure and the amino acid sequences of the two enzymes encoded by this operon. Proline synthesis from glutamate is regulated mainly through proline-mediated feedback inhibition of GK, the first enzyme in the pathway.

Strain SP187 described above was obtained by four rounds of mutagenesis and selection. This strain has the put $A$ mutation, abolishing proline oxidase activity, and shows resistance to the proline analogues 3,4-DLdehydroproline (DHP), L-thiazolidine-4-carboxylic acid (TAC) and L-azetidine-2-carboxylic acid (Sugiura \& Kisumi, 1985a). Transductional analysis suggested that the DHP resistance mutation, designated the $d p r-1$ genotype, might be closely linked to the proBA region but we had no further information on this mutation (Sugiura \& Kisumi, 1985a).

In the work described here, we determined and analysed the nucleotide sequence of the mutant proBA 
operon, which was previously cloned from strain SP187 (Takagi et al., 1985).

\section{Methods}

Strains, plasmids and media. The strains and plasmids are listed in Table 1. E. coli JM109 was used for the construction of plasmids. The rich medium used was LB (Davis et al., 1980); the minimal medium of Davis \& Mingioli (1950) was modified by omitting the sodium citrate and supplemented with $0.5 \%$ glucose or $0.5 \%$ disodium succinate hexahydrate as a carbon source. Required $L$-amino acids were used at $1 \mathrm{mM}$. Antibiotics were added at the following concentrations: kanamycin $(\mathrm{Km}), 200 \mu \mathrm{g} \mathrm{ml}^{-1}$; ampicillin (Ap), $200 \mu \mathrm{g} \mathrm{ml}^{-1}$.

General methods. DNA manipulations were carried out according to standard procedures (Maniatis et al., 1982). Transformation of E. coli or $S$. marcescens was done as described by Takagi \& Kisumi (1985).

$D N A$ sequencing. The nucleotide sequence of the plasmid containing the mutant-type proBA genes from $S$. marcescens SP187 was determined by dideoxy chain-termination method (Sanger $e t$ al., 1977) with the aid of a sequencing system purchased from Takara Shuzo (Kyoto, Japan). After subcloning DNA fragments into pUC18, pUC19, pHSG298 and pHSG299, ordered deletion subclones were obtained by unidirectional digestion (Yanisch-Perron et al., 1985). The DNA chains were labelled with $\left[\alpha^{-32} \mathrm{P}\right] \mathrm{dCTP}\left(400 \mathrm{Ci} \mathrm{mmol}^{-1} ; 15 \mathrm{TBq}\right.$ $\left.\mathrm{mmol}^{-1}\right)$. Nucleotide sequence data were analysed by using the computer program GENETYX (Software Development, Japan).

Proline excretion. To determine the mutation responsible for proline overproduction, we constructed four hybrid proBA plasmids containing mutations in the proBA operon. The $2.9 \mathrm{~kb}$ BamHI-EcoRI proBA fragments of pWP142 and pYI720 were subcloned into the corresponding sites of pLG339 to give pWPK342 (wild-type) and pYIK 920 (mutant), respectively. Plasmid pWPK100, carrying the Ppro2 mutation, was constructed by replacing the $0.4 \mathrm{~kb} N c o I-A v a I$ fragment containing the promoter region of pWPK 342 with one isolated from pYIK920 (see Fig. 1). Plasmid pWPK010, carrying the proBl mutation, was obtained by replacing the $0.9 \mathrm{~kb}$ Aval-SphI fragment containing the proB gene of pWPK 342 with one isolated from pYIK920 (see Fig. 1). S. marcescens TT392 was used as a host for these plasmids.

Proline excretion was determined by an auxanographic cross-feeding test using a proline auxotroph, $S$. marcescens SP139 (Sugiura et al., 1985). A minimal agar plate seeded with this strain at $5 \times 10^{8} \mathrm{cells} \mathrm{ml}^{-1}$ was spotted with cells of the strain to be tested and incubated at $30^{\circ} \mathrm{C}$ for 24-48 h. Excretion was scored positive if a halo of satellite growth of the indicator cells was observed.

Assay of enzyme activity. Cells were grown at $30^{\circ} \mathrm{C}$ in $500 \mathrm{ml}$ flasks containing $200 \mathrm{ml}$ minimal medium. For the assay of GK activity the cells were harvested in the exponential growth phase, washed with $50 \mathrm{~mm}$-Tris/ $\mathrm{HCl}$ ( $\mathrm{pH} \mathrm{7.2)}$ containing $1 \mathrm{~mm}$-dithiothreitol and disrupted by sonication. The cell extracts were desalted with a Pharmacia PD-10 column and used for hydroxamate assay of GK activity as described by Hayzer \& Leisinger (1980). The standard assay, containing $50 \mathrm{~mm}$ L-glutamate, was used. The difference between values with and without the addition of $1 \mathrm{M}$-L-proline to the reaction mixture represented the proline-inhibitable GK activity. The proline-inhibitable GK of $S$. marcescens TT392 containing pWPK010 was inhibited by $1 \mathrm{M}$ L-proline to the level of the same strain without the plasmid.

For the assay of $\beta$-galactosidase, cells were harvested in the exponential growth phase, washed with saline, and resuspended in $100 \mathrm{~mm}$-sodium phosphate buffer ( $\mathrm{pH} 7 \cdot 0)$ containing $10 \mathrm{mM}-\mathrm{KCl}$, $1 \mathrm{mM}-\mathrm{MgSO}_{4}$ and $50 \mathrm{~mm}$-2-mercaptoethanol. After disruption by
Table 1. Bacterial strains and plasmids

\begin{tabular}{|c|c|c|}
\hline $\begin{array}{l}\text { Strain } \\
\text { or } \\
\text { plasmid }\end{array}$ & Genotype or phenotype ${ }^{*}$ & Source or reference \\
\hline \multicolumn{3}{|l|}{ E. coli $\mathrm{K} 12$} \\
\hline JM109 & $\Delta($ lac-proBA $)$ thi & $\begin{array}{l}\text { Yanisch-Perron } \\
\text { et al. (1985) }\end{array}$ \\
\hline \multicolumn{3}{|c|}{ S. marcescens $\mathrm{Sr} 4 \mathrm{I}$} \\
\hline TT392 & $\mathrm{Nuc}^{-} \mathrm{r}^{-} \mathrm{Ap}^{\mathrm{s}} \mathrm{Km}^{\mathrm{s}}$ & $\begin{array}{l}\text { Takagi \& Kisumi } \\
(1985)\end{array}$ \\
\hline SP103 & putA & Sugiura et al. (1985) \\
\hline SP139 & putA proB $/ A$ & Sugiura et al. (1985) \\
\hline \multicolumn{3}{|l|}{ Plasmids } \\
\hline pBR322 & $A p^{r} T c^{r}$ & Bolivar et al. (1977) \\
\hline pLG339 & $\mathrm{Km}^{\mathrm{r}} \mathrm{T} \mathrm{c}^{\mathrm{r}}$ & $\begin{array}{l}\text { Stocker et al. (1982); } \\
\text { derived from } \\
\text { pSC101 }\end{array}$ \\
\hline $\left.\begin{array}{l}\text { pUC18 } \\
\text { pUC19 }\end{array}\right\}$ & $A p^{r} l a c Z \alpha$ & $\begin{array}{l}\text { Yanisch-Perron } \\
\text { et al. (1985) }\end{array}$ \\
\hline $\left.\begin{array}{l}\text { pHSG } 298 \\
\text { pHSG299 }\end{array}\right\}$ & $\mathrm{Km}^{\mathrm{r}} \operatorname{lac} \mathrm{Z} \alpha$ & $\begin{array}{l}\text { Takeshita et al. } \\
\text { (1987) }\end{array}$ \\
\hline pLGlacZ1 & $\begin{array}{l}\text { pLG339::lac' } Z \\
\text { pKP1154::Ppro2 proB } / A^{+}\end{array}$ & $\begin{array}{l}\text { Omori et al. (1991) } \\
\text { Takagi et al. }(1985)\end{array}$ \\
\hline pYI720 & pBR322::Ppro2 proB $1 A^{+}$ & This study \\
\hline pWP142 & pBR322::pro $B^{+} A^{+}$ & Omori et al. (1991) \\
\hline pWPK 342 & pLG339::proB $B^{+} A^{+}$ & This study \\
\hline pYIK920 & pLG339::Ppro2 proBlA ${ }^{+}$ & This study \\
\hline pWPK 100 & pLG339::Ppro2 pro $^{+} A^{+}$ & This study \\
\hline pWPK010 & pLG339::proB $1 A^{+}$ & This study \\
\hline pWPL10 & pLGlacZ1 ::Ppro ${ }^{+}$proB & Omori et al. (1991) \\
\hline pYILI0 & pLGlacZ1::Ppro2 proB' & This study \\
\hline
\end{tabular}

* Symbols used for relevant genotypes and phenotypes are as follows: Nuc $^{-}$, no production of extracellular nuclease; $\mathrm{r}^{-}$, defect of a host restriction enzyme; put $A$, destruction of proline oxidase; proB/A, proline auxotrophy; Ppro, promoter of the proBA genes; Ppro2, upmutation in the promoter enhancing transcription of the proline operon, located in the spacer region; proBl, lack of feedback inhibition of GK.

sonication, the resultant cell extracts were used for the assay of $\beta$-galactosidase. $\beta$-Galactosidase activities were measured using $o$-nitrophenyl $\beta$-D-galactoside as a substrate (Miller, 1972).

The units of GK and $\beta$-galactosidase activities are nmol product formed $\mathrm{min}^{-1}$ (mg protein) ${ }^{-1}$. Protein concentration was determined by the use of a Bio-Rad protein assay kit with bovine serum albumin as the standard.

Analysis of proB-lac $Z$ expression. The transcriptional activity of the proBA promoter was measured by using the plasmid pLGlacZl (Omori et al., 1991). We constructed a gene fusion by ligating the beginning of the lac $Z$ structural gene in-frame to the region containing the proBA promoter and the $5^{\prime}$ terminus of the proB gene. The proB-lac $Z$ gene fusion plasmid, pYIL10, was constructed by cloning the $0.3 \mathrm{~kb}$ BamHI-SacII fragment of pYI720 into the filled-in BamHI site of pLGlacZl (see Fig. 4). The proline-oxidase-deficient mutant of $S$. marcescens, SP103, was used as a host to prevent the degradation of L-proline added to the medium (Sugiura et al., 1985).

In vitro transcription-translation analysis of plasmid DNAs. The prokaryotic cell-free coupled transcription-translation system from Amersham was employed for labelling proteins encoded by plasmids. 


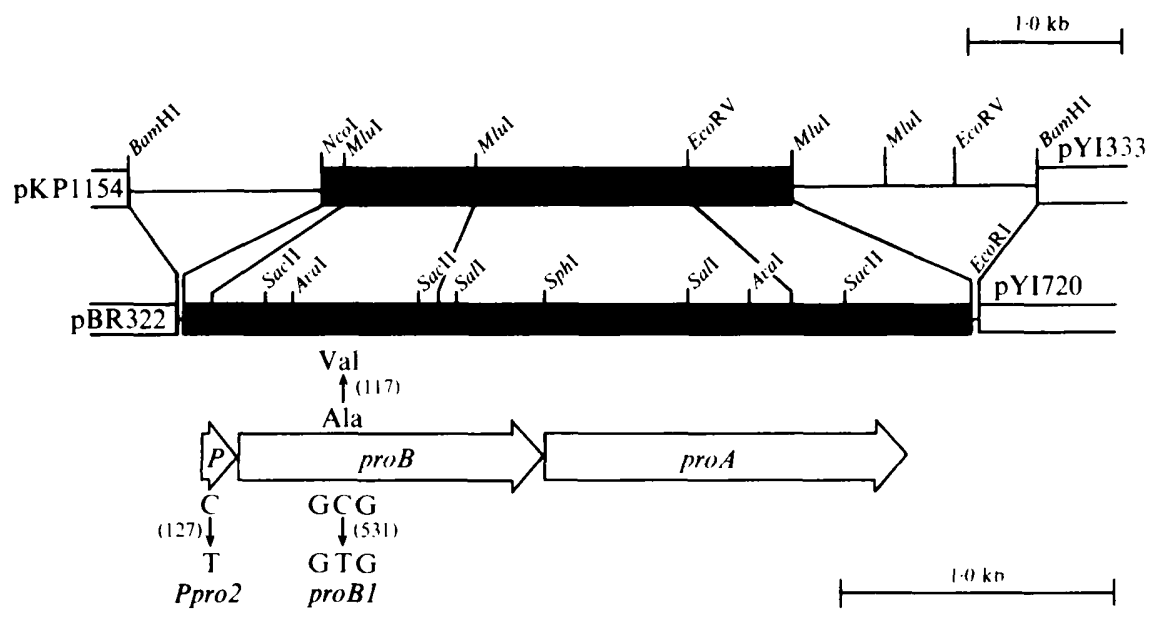

Fig. 1. Restriction maps of the proBA plasmids pYI333 and pYI720, and the base substitutions found in the mutant proBA operon. The restriction sites indicated on the map are defined. Open arrows show the ORFs and the promoter region $(P)$ of the proBA operon. The positions of two base substitutions, Ppro 2 and $\operatorname{proBl}$, and the resultant amino acid substitution in the proBA operon, are indicated.

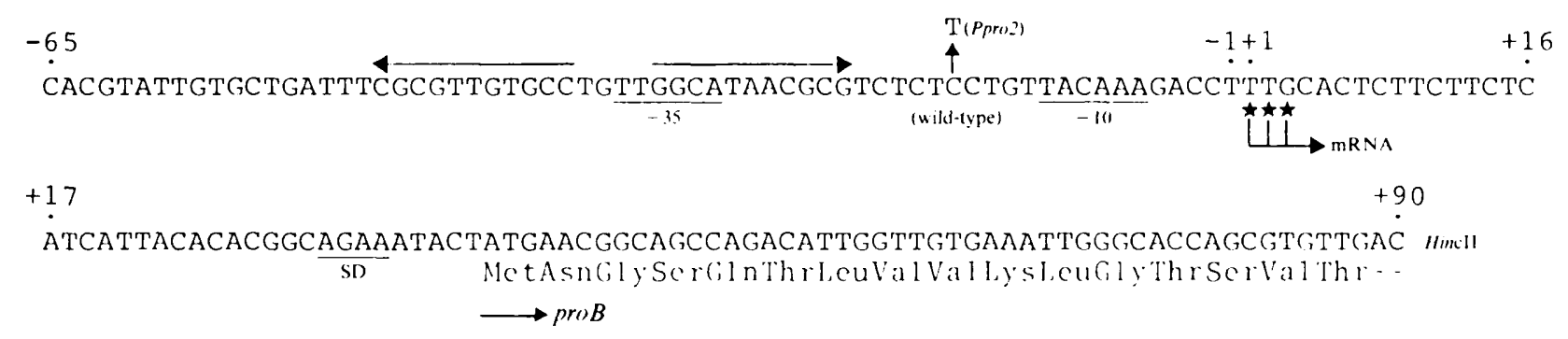

Fig. 2. Base substitution found in the promoter region of the proBA operon. The nucleotide sequence of the promoter region of the mutant is shown. The distance in base pairs from the first transcription start site, which is designated +1 , is given above the sequence. Potential ${ }^{\prime}-10^{\prime}$ and ${ }^{\circ}-35^{\circ}$ sequences are underlined. A region of dyad symmetry, centred at position $107-108(-34-35)$, is shown by inverted arrows. The base change from a $\mathrm{C}$ to a $\mathrm{T}$ at nucleotide $127(-16)$ is indicated by an arrow.

Plasmid DNA $(0.4 \mu \mathrm{g})$, prepared by $\mathrm{CsCl}$ density-gradient centrifugation, was added to the reaction mixture $(5 \mu l)$ containing $L-\left[{ }^{35} S\right]$ methionine, according to the manufacturer's protocol. SDS-PAGE of ${ }^{35} \mathrm{~S}$-labelled proteins was carried out as described by Laemmli (1970). Labelled polypeptide bands were visualized by autoradiography.

Sensitivities to osmotic stress and to proline analogues. Osmotolerance and proline analogue resistance were measured as described by Sugiura et al. (1985). To determine the sensitivity to osmotic stress, we used a put $^{+}$strain, $S$. marcescens TT392, as host. Cells harbouring pWPK 342, pWPK 100 or pWPK010 were grown at $30^{\circ} \mathrm{C}$ in the minimal medium containing $0.5 \%$ glucose as carbon source with or without the addition of $0.6 \mathrm{M}-\mathrm{NaCl}$ to increase osmolarity. To examine proline analogue sensitivity, the put $A$ strain $S$. marcescens SPI03 was used, to prevent the degradation of L-proline and proline analogues. To determine the sensitivities to DHP and TAC, cells carrying the above plasmids were grown in the minimal medium containing $0.5 \%$ glucose or $0.5 \%$ sodium succinate, respectively. Growth was estimated turbidimetrically at $660 \mathrm{~nm}$ with a Hitachi electric photometer (EPO-B type).

\section{Results}

Base substitutions in the mutant proBA operon

The mutant proBA operon from strain SP187 had been previously cloned into pKP1154, resulting in plasmid pYI333 (Takagi et al., 1985). The $2.9 \mathrm{~kb}$ NcoI-MluI fragment of this plasmid was subcloned in the BamHIEcoRI interval of pBR322, creating pYI720, and was confirmed to contain the entire proBA genes by a complementation test. The structure of pYI720 carrying the mutant proBA operon was shown to be identical by restriction analysis to that of pWP142 carrying the wildtype proBA (Omori et al., 1991). The complete nucleotide sequence of the insert carried by pYI720 was determined. Subsequently, this insert was confirmed to 


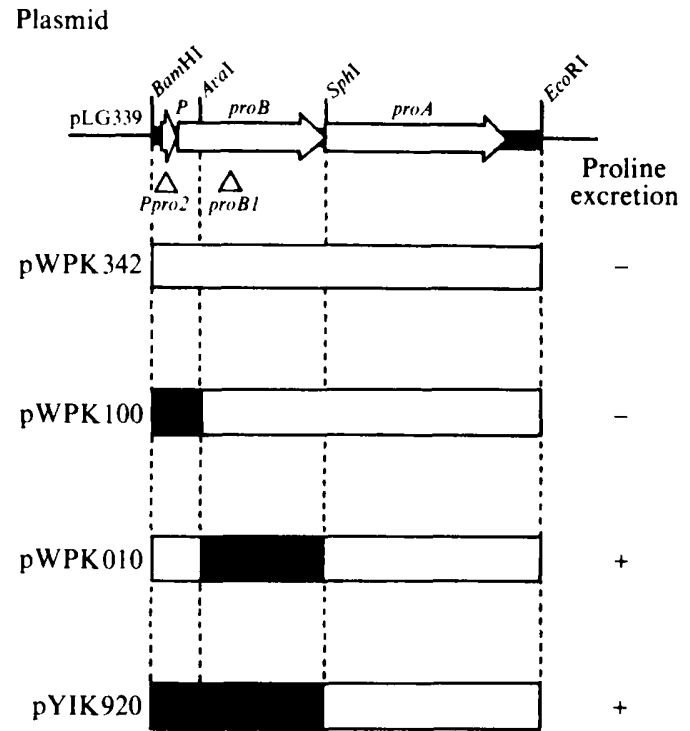

Fig. 3. Hybrid plasmid analysis of the mutations responsible for proline overproduction. $S$. marcescens TT392 was used as the host for plasmids. Proline excretion was detected by the presence of a halo of satellite growth of the indicator, $p r o B / A$ strain SP139, surrounding the colony. The regions derived from the wild-type and mutant-type proBA operons are indicated by open and filled boxes, respectively. The promoter region of the proBA operon is indicated by $P$. The relative positions of amino acid substitutions are shown by open triangles. include the two open reading frames coding for $\mathrm{GK}$ and GPR, a promoter region, and a terminator region. Nucleotide sequence comparisons with the wild-type proBA operon revealed two base substitutions in the mutant-type operon (Fig. 1). One, designated Ppro2, was a $\mathrm{G}-\mathrm{C}$ to $\mathrm{A}-\mathrm{T}$ transversion at nucleotide 127 , in the spacer between the ' -35 ' and ' -10 ' sequences (Fig. 2). The other, designated proBI, was a $\mathrm{G}-\mathrm{C}$ to $\mathrm{A}-\mathrm{T}$ transversion at nucleotide 531 in the proB structural gene. This substitution predicts an amino acid substitution from an alanine to a valine at amino acid residue 117 in the mutant GK. Although the proline-overproducing mutation in the pro operon of strain SP187 was previously designated $d p r-1$ (Sugiura \& Kisumi, 1985a), here we have found that this mutation consists of two base substitutions in the operon. In this paper, we use Ppro2 and proBl as genotypes of the mutations.

\section{Effects of the individual base substitutions on proline production}

We subcloned the wild-type and the mutant proBA fragments into a low-copy-number vector, pLG339, for stable expression of the proBA operon, generating pWPK342 and pYIK920, respectively. To elucidate the

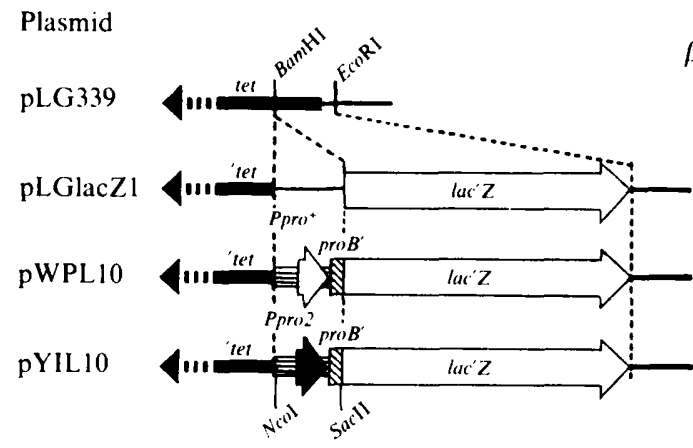

Specific activity of $\beta$-galactosidase (units)

$$
<10
$$

Fig. 4. Constitution of proB-lac $Z$ fusion plasmids and level of $\beta$-galactosidase activity in $S$. marcescens SP103 (putA). Restriction sites used for plasmid construction are indicated. Cells were grown in the minimal medium containing glucose as described in Methods.

Table 2. Resistance to osmotic stress and to proline analogues of S. marcescens harbouring different plasmids

The host strain was $S$. marcescens SP103, grown in minimal medium with the additions shown.

\begin{tabular}{|c|c|c|c|c|c|c|c|c|}
\hline \multirow[b]{3}{*}{ Plasmid } & \multicolumn{8}{|c|}{ Generation time (h) } \\
\hline & \multicolumn{5}{|c|}{ C source glucose } & \multicolumn{3}{|c|}{ C source succinate } \\
\hline & Control & $0.6 \mathrm{M}-\mathrm{NaCl}$ & $\begin{array}{c}0.6 \mathrm{M}-\mathrm{NaCl}+ \\
1 \mathrm{mM}-\mathrm{L}-\mathrm{Pro}\end{array}$ & $1 \mathrm{mM}-\mathrm{DHP}$ & $\begin{array}{c}1 \mathrm{mM}-\mathrm{DHP}+ \\
1 \mathrm{mM}-\mathrm{L}-\mathrm{Pro}\end{array}$ & Control & $10 \mathrm{mM}-\mathrm{TAC}$ & $\begin{array}{c}10 \mathrm{mM}-\mathrm{TAC}+ \\
1 \mathrm{mM}-\mathrm{L}-\mathrm{Pro}\end{array}$ \\
\hline pWPK 342 & $1 \cdot 1$ & $>10$ & $2 \cdot 6$ & $>10$ & $1 \cdot 2$ & $1 \cdot 7$ & $>10$ & $3 \cdot 6$ \\
\hline pWPK 100 & $1 \cdot 1$ & $>10$ & $2 \cdot 5$ & $>10$ & 1.0 & 1.8 & $>10$ & 3.5 \\
\hline pWPK 010 & 1.6 & 2.5 & $2 \cdot 3$ & 1.6 & 1.5 & 2.9 & $>10$ & $3 \cdot 2$ \\
\hline
\end{tabular}




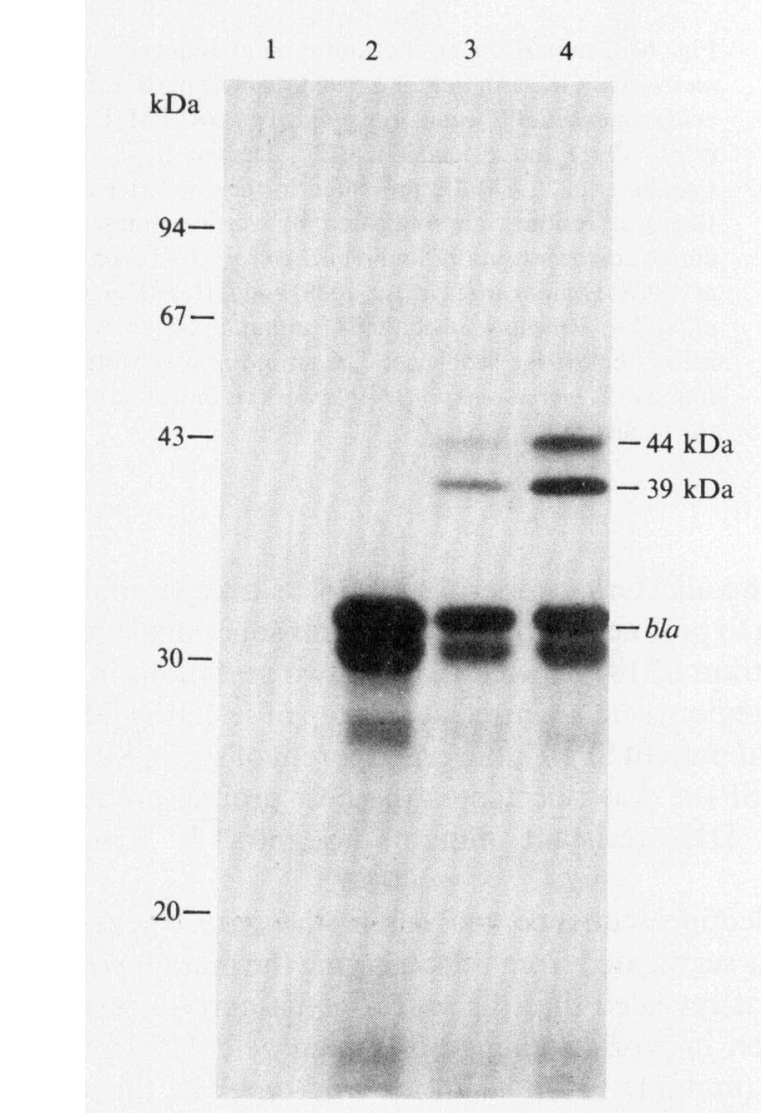

Fig. 5. Analysis of polypeptides encoded by plasmids carrying the wild-type and mutant proBA genes. Plasmid-specified polypeptides were produced in S-30 cell-free extract from $E$. coli. The ${ }^{35} \mathrm{~S}$-labelled polypeptides synthesized in vitro were analysed by SDS-PAGE $(12.5 \%$, $w / v$, acrylamide) and visualized by autoradiography. Lane 1 , no plasmid; lane 2, pBR322; lane 3, pWP142; lane 4, pYI720. The migration of protein standards is indicated on the left. bla indicates $\beta$-lactamase encoded by the plasmids used.

effects of each mutation on proline production, two proBA plasmids, pWPK 100 and pWPK010, containing either the Ppro2 or the proBl mutation, respectively, were constructed. The mutant and the wild-type proBA plasmids were introduced into cells of $S$. marcescens TT392 (wild-type) and tested for proline excretion (Fig. 3). Plasmids pWPK010 and pYIK920, carrying the proBl mutation, exhibited proline excretion, while cells containing the pro $^{+}$plasmids, pWPK 342 (wild-type) and pWPK 100 (Ppro2), did not excrete proline. These results indicated that the proBI mutation, a base substitution in the proB gene, which predicts an amino acid substitution from an alanine to a valine at amino acid residue 117 in the mutant-type GK, causes the proline overproduction. No difference in proline excretion was observed between pWPK010, carrying the proBl mutation, and pYIK 920, carrying both Ppro2 and proBI mutations.

\section{Lack of feedback inhibition of $G K$ encoded by the proBI gene}

We have previously reported that the wild-type GK produced by the plasmid carrying the wild-type pro $B A$ operon is very sensitive to proline-mediated feedback inhibition (Omori et al., 1991). The activity of GK produced by the proBI plasmid, pWPK010, was examined for feedback inhibition. The concentration of L-proline causing $50 \%$ inhibition was $11 \mathrm{~mm}$ for the mutant GK and $0.016 \mathrm{~mm}$ for the wild-type (results not shown).

\section{Elevated expression of the proBA operon caused by the Ppro2 mutation}

To examine the effect of the Ppro2 mutation on gene expression, we constructed the proB-lac $Z$ gene fusion plasmid pYIL10, carrying the Ppro2 mutation, as described for pWPL10 by Omori et al. (1991). $\beta$-Galactosidase activities were examined using cells harbouring each of the two gene fusion plasmids (Fig. 4). The promoter carrying the Ppro2 mutation showed about fourfold greater transcriptional activity than the wildtype promoter. SDS-PAGE analysis of in vitro protein synthesis confirmed the overproduction of the GPR and GK proteins, of 44 and $39 \mathrm{kDa}$, respectively, directed by the plasmid pY1720, carrying the Ppro2 mutation (Fig. 5).

The role of the two regulatory mutations in osmotolerance and in proline analogue resistance

We determined the sensitivities to osmotic stress and to proline analogues of $S$. marcescens SP103 harbouring the Ppro2 and proBI plasmids (Table 2). Cells carrying the plasmid with the wild-type $\operatorname{pro}^{+} A^{+}$operon, pWPK 342 , showed high sensitivities to an increased osmolarity and to the proline analogue DHP. The Ppro2 plasmid, pWPK 100, was similar to the wild-type plasmid in the sensitivities it conferred to osmolarity and DHP. Although the proBI plasmid, pWPK010, impaired the growth rate of its host in media of normal osmolarity, it conferred an enhanced tolerance to osmotic stress and a high resistance to DHP. However, this plasmid did not give TAC resistance to its host.

Cells harbouring pYIK 920, which carries both Ppro2 and proBl mutations, grew more slowly than those harbouring the proBl plasmid, pWPK010. Plasmid pYIK 920 was unstable in $S$. marcescens and cells carrying this plasmid segregated mutants that no longer excreted proline. Plasmids isolated from these mutants could complement the proBA mutation. Nucleotide sequence analysis of these plasmid DNAs revealed a 


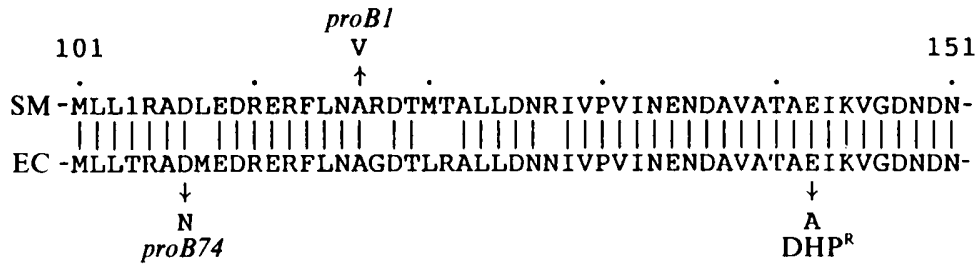

Fig. 6. Comparison of the amino acid sequence of $S$. marcescens GK with that of $E$. coli GK. The partial amino acid sequences of $S$. marcescens wild-type GK (SM;Omori et al., 1991) and E. coli GK (EC; Deutch et al. 1984; Csonka et al., 1988) are presented in the one-letter code. Identical residues are indicated by vertical lines. The amino acid substitutions found in E. coli proB 74 (Csonka $e t$ al., 1988; Dandekar \& Uratsu, 1988) and DHPR (Deutch et al., 1984; Rushlow et al., 1984) mutants are shown by arrows below the sequence. The amino acid substitution found in $S$. marcescens proBl (this work) is indicated above the sequence. base substitution at nucleotide 531 that predicted a change of the amino acid 117 from a valine (mutant) to an alanine (wild-type) in the GK protein.

\section{Discussion}

Our results indicate that $S$. marcescens SP187, a prolinehyperproducing mutant, possesses two mutations in the proBA operon. The proline overproduction and the resultant resistance to both osmotic stress and a proline analogue are due to one of these mutations, proBl. This mutation is a single base substitution in the pro $B$ gene which directs an amino acid substitution of the GK protein. The GK enzyme specified by this mutant-type pro $B$ gene is 700 -fold less sensitive to proline-mediated feedback inhibition than the wild-type. Another mutation, Ppro2, is a base substitution located in the spacer region of the promoter (Hawley \& McClure, 1983; Harley \& Reynolds, 1987).

The Ppro2 mutation stimulates expression of proBA fourfold over that of the wild-type. Expression of proBA is unlikely to be subject to any transcriptional regulation (Omori et al., 1991). Hence, enhanced proBA expression caused by the Ppro2 mutation is not likely to be due to a loss of repression but rather to the up-mutation of the promoter. Up-mutations in the spacer region have been reported in the lac (Dickson et al., 1975) and gal (Busby et al., 1984) promoters of $E$. coli. Stefano \& Gralla (1982) have proposed that the spacer region is responsible for the local conformation of the ' -10 ' and ' -35 ' regions which make contact with RNA polymerase. The Ppro2 mutation may cause a subtle change in the conformation of the DNA of the promoter region. Although the Ppro2 mutation alone confers neither proline excretion nor resistance to osmotic stress and proline analogues, it results in the overproduction of the GK and GPR proteins, and consequently enhances proline production. This indicates that in $S$. marcescens, the regulation of proline synthesis depends mainly on the feedback inhibition of GK and that the proBl mutation which alters the allosteric properties of GK is a key mutation leading to proline overproduction. Transductional analysis of strain SP187 showed that the two mutations in the proBA region were acquired at the step of selecting DHPresistant mutant SP105, the grandparent of strain SP187. Strain SP105 was selected as the best proline producer among DHP-resistant mutants (Sugiura \& Kisumi, 1985a).

Nucleotide sequence analysis of the proBA genes of mutants segregated from cells carrying the mutant pro $B A$ plasmids revealed that the $\operatorname{pro} B A$ genes carry a reverse mutation in proB, a change of amino acid 117 from a valine (mutant) to an alanine (wild-type) in the GK protein. This mutation is the cause of the loss of proline productivity reported by Takagi et al. (1985).

$S$. marcescens is similar to $E$. coli in the structure of the proBA operon (Omori et al., 1991). The GK proteins produced by both bacteria consist of 367 amino acid residues and homology between them is $88 \%$. In E. coli, proB mutants resistant to a proline analogue and overproducing proline have been isolated (Csonka, 1981; Mahan \& Csonka, 1983; Smith et al., 1984). The proB mutations, $D H P^{R}$ and proB74, result in a loss of allosteric inhibition of GK and depend on single amino acid substitutions: at amino acid residues 143 and 107 in the DHPR GK and proB74 GK, respectively (Csonka et al., 1988; Dandekar \& Uratsu, 1988; Rushlow et al., 1984). The $S$. marcescens proB mutation reported here, designated proBl, predicts an amino acid substitution at amino acid residue 117 in the GK protein. These three amino acid substitutions are all located in a region (amino acid residues 107-143) which lies apart from the sequence (amino acid residues 160-190) homologous to aspartokinase (Omori et al., 1991) (Fig. 6). The $S$. marcescens proBI and $E$. coli proB 74 mutations confer osmotolerance on the cells, but the DHPR mutation does not. This region of GK is probably important for binding of proline to the allosteric site of the wild-type GK. Further kinetic studies of the mutant GKs, analysis of the other DHP resistance mutations, and X-ray crystallographic analysis of mutant-type GKs, should clarify this. 
We thank Dr I. Chibata, Dr T. Tosa and Dr T. Sato for encouragement, and $\mathrm{Dr} \mathrm{T}$. Takagi for helpful discussion.

\section{References}

Aspinall, D. \& Paleg, L. G. (1981). Proline accumulation: physiological aspects. In Physiology and Biochemistry of Drought Resistance in Plants, pp. 206-241. Edited by L. G. Paleg \& D. Aspinall. New York: Academic Press.

Bolivar, F., Rodriguez, R. L., Greene, P. J., Betlach, M. C., Heynecker, H. L., Boyer, H. W., Crosa, J. H. \& Falkow, S. (1977). Construction and characterization of new cloning vehicles. II. A multipurpose cloning system. Gene 2, 95-113.

Busby, S., Truelle, N., Spassky, A., Dreyfus, M. \& Buc, H. (1984). The selection and characterization of two novel mutations in the overlapping promoters of the Escherichia coli galactose operon. Gene 28, 201-209.

Csonka, L. N. (1981). Proline overproduction results in enhanced osmotolerance in Salmonella typhimurium. Molecular and General Genetics 182, 82-86.

CSONKa, L. N., Gelvin, S. B., GoOdner, B. W., OrSer, C. S., Siemieniak, D. \& Slightom, J. L. (1988). Nucleotide sequence of a mutation in the proB gene of Escherichia coli that confers proline overproduction and enhanced tolerance to osmotic stress. Gene 64, 199-205.

DandeKar, A. M. \& Uratsu, S. L. (1988). A single base pair change in proline biosynthesis genes causes osmotic stress tolerance. Journal of Bacteriology 170, 5943-5945.

DAvis, B. D. \& Mingioli, E. S. (1950). Mutation of Escherichia coli requiring methionine or vitamin $B_{12}$. Journal of Bacteriology 60 , 17-28.

Davis, R. W., Botstein, D. \& Roth, J. R. (1980). Advanced Bacterial Genetics. A Manual for Genetic Engineering. Cold Spring Harbor, NY: Cold Spring Harbor Laboratory.

Deutch, A. H., Rushlow, K. E. \& Smith, C. J. (1984). Analysis of the Escherichia coliproBA locus by DNA and protein sequencing. Nucleic Acids Research 12, 6337-6355.

Dickson, R. C., Abelson, J., Barns, W. M. \& Reznikoff, W. S. (1975). Genetic regulation: the lac control region. Science 187, 27-35.

HaRley, C. B. \& ReYNolds, R. P. (1987). Analysis of E. coli promoter sequences. Nucleic Acids Research 15, 2343-2361.

HAWLEY, D. K. \& MCCluRE, W. R. (1983). Compilation and analysis of Escherichia coli promoter DNA sequences. Nucleic Acids Research 11, 2237-2255.

HAYZER, D. J. \& LEISINGER, T. (1980). The gene-enzyme relationships of proline biosynthesis in Escherichia coli. Journal of General Microbiology 118, 287-293.

LAEMmLi, U. K. (1970). Cleavage of structural proteins during the assembly of the head of bacteriophage T4. Nature, London 227, 680-685.

Mahan, M. J. \& Csonka, L. N. (1983). Genetic analysis of the proBA genes of Salmonella typhimurium: physical and genetic analysis of the cloned proB $B^{+} A^{+}$genes of Escherichia coli and of a mutant allele that confers proline overproduction and enhanced osmotolerance. Journal of Bacteriology 156, 1249-1262.

Maniatis, T., FirTsCh, E. F. \& SAmbrooK, J. (1982). Molecular Cloning: a Laboratory Manual. Cold Spring Harbor, NY: Cold Spring Harbor Laboratory.

Miller, J. (1972). Experiments in Molecular Genetics. Cold Spring Harbor, NY: Cold Spring Harbor Laboratory.

MEASURES, J. C. (1975). Role of amino acids in osmoregulation of nonhalophilic bacteria. Nature, London 257, 398-400.

Omori, K., Suzuki, S., Imai, Y. \& Komatsubara, S. (1991). Analysis of the Serratia marcescens proBA operon and feedback control of proline biosynthesis. Journal of General Microbiology 137, 509-517.

Rushlow, K. E., DeUTCH, A. H. \& SMITH, C. J. (1984). Identification of a mutation that relieves gamma-glutamyl kinase from allosteric feedback inhibition by proline. Gene 39, 109-112.

SANGer, F., Nicklen, S. \& Coulson, A. R. (1977). DNA sequencing with chain-termination inhibitors. Proceedings of the National Academy of Sciences of the United States of America 74, 5463-5467.

Smith, C. J., Deutch, A. H. \& Rushlow, K. E. (1984). Purification and characteristics of a $\gamma$-glutamyl kinase involved in Escherichia coli proline biosynthesis. Journal of Bacteriology 157, 545-551.

Stefano, J. E. \& Gralla, J. D. (1982). Spacer mutations in the lac PS promoter. Proceedings of the National Academy of Sciences of the United States of America 79, 1069-1072.

Stocker, N. G., Fairweather, N. F. \& Spratt, B. G. (1982). Versatile low-copy-number plasmid vectors for cloning in Escherichia coli. Gene 18, 335-341.

SUGIURA, M. \& KISUMI, M. (1985a). Proline-hyperproducing strains of Serratia marcescens: enhancement of proline analog-mediated growth inhibition by increasing osmotic stress. Applied and Environmental Microbiology 49, 782-786.

Sugiura, M. \& Kisumi, M. (1985b). Increase in the intracellular concentration of a proline analog during high osmotic stress in Serratia marcescens. Agricultural and Biological Chemistry 49, 3063-3064.

Sugiura, M., Takagi, T. \& Kisumi, M. (1985). Proline production by regulatory mutants of Serratia marcescens. Applied Microbiology and Biotechnology 21, 213-219.

TAKAGI, T. \& KisUMI, M. (1985). Isolation of a versatile Serratia marcescens mutant as a host and molecular cloning of the aspartase gene. Journal of Bacteriology 161, 1-6.

Takagi, T., Imai, Y., Sugiura, M. \& Kisumi, M. (1985). Stability and instability of a cloned mutant allele of the proline gene in Serratia marcescens. Use of a mini-F plasmid in the proline-overproducing mutant. Journal of Biotechnology 3, 59-71.

Takeshita, S., Sato, M., Toba, M., Masahashi, W. \& HashimotoGотон, T. (1987). High-copy-number and low-copy-number plasmid vectors for lac $Z \alpha$-complementation and chloramphenicol- or kanamycin-resistance selection. Gene 61, 63-74.

YANISCh-PerRon, C., Vieira, J. \& Messing, J. (1985). Improved M13 phage cloning vectors and host strains: nucleotide sequences of the M13mp18 and pUC19 vectors. Gene 33, 103-119. 